\section{TRACE ELEMENTS IN RELATION TO HEALTH}

$\mathrm{T}$ HE eighth scientific meeting of the recently formed Nutrition Society, or fifth of the English group, took the form of a whole-day conference at the London School of Hygiene and Tropical Medicine, on "Trace Elements in Relation to Health".

Dr. J. Russell Greig occupied the chair at the morning session, opening the proceedings with a brief reference to his own interest in 'pining' of sheep in Scotland. Prof. C. Harington took the chair at the afternoon session and finally summed up the day's discussion as a whole. Ten papers provided by fourteen contributors were included on the agenda paper, all of which will be published in due course in the Proceedings of the Nutrition Society.

(1) Significance of Trace Elements in Relation to Diseases of Plants and Animals. In this paper Dr. H. H. Green, of the Veterinary Laboratory of the Ministry of Agriculture at Weybridge, offered a 'bird's-eye view' over the whole field of trace elements of known economic importance in both plant and animal life, intended to serve as an introduction to the more specialized papers to follow. Commencing with a definition of 'trace element' as any element regularly occurring in minute amounts in living tissues whether it exercises any specific physiological function or not, metals such as aluminium and nickel were cited as apparently inert and merely present because incidentally taken up by the action of plant roots; elements such as copper and manganese cited as essential for both plants and animals, boron as essential for the plant but not known to be essential for the animal, cobalt as essential for cattle and sheep but not yet known to be essential for non-ruminants or for plants, selenium and molybdenum as probably unessential for both plants and animals but sometimes taken up by healthy plants in amounts which cause disease in the consuming animal.

Omitting elements such as lead and arsenic which, though known to be toxic, are not absorbed by plants in amounts dangerous to animals, and passing over the essential element iodine as "trace but no longer novel", the elements copper, cobalt, manganese, zine and boron, were dealt with in some detail as involved in deficiency diseases, and fluorine, selenium and molybdenum as causing toxicoses.

The occurrence of relevant plant and animal ailments in various parts of the world was summarized, local names, prominent symptoms and methods of control being mentioned. Control varies from fertilizing apple trees with borax in Tasmania for control of 'internal cork', or pine trees in Australia for 'needle fusion', top dressing pastures with copper sulphate for control of 'Urbarmachungskrankeit' in crops and 'Lecksucht' in animals in SchleswigHolstein, or for control of 'falling disease' of ruminants in Australia, providing copperized salt licks to breeding sheep for protection against 'swayback' of lambs in England or 'enzootic ataxia' in other parts of the world, supplying cobalt to prevent 'wasting disease' of cattle and sheep in Australia, 'Grand Traverse disease' in Michigan, and 'pining' in Scotland, to controlling the 'alkali disease' of Dakota or the 'blind staggers' of Wyoming by eradicating plants which take up excessive quantities of selenium from seleniferous shales and act as 'selenium converters' by finally returning that toxic element to the soil in a form more available for other plants.
The quantities of essential trace elements in plants are, however, no necessary indication of the quantities required by consuming animals, and animals may waste away when grazing on luxuriant herbage or complete the cycle of their being on plants showing obvious symptoms of vegetative failure.

(2) Distribution of Trace Elements in Soils and Grasses. Dr. R. L. Mitchell, of the Macauley Institute, near Aberdeen, pointed out that a very large number of elements is present in soils, each in traces of fractional parts per million upwards, but that the amount of any one of them may vary a thousand-fold from soil to soil. The variations correspond to the parent material from which the soil is derived, in the last resort from igneous rocks and the magmas from which they have crystallized; but certain geoch element occurs in a rock there must be present in it a mineral at least one of the constituents of which can be replaced by an atom of the element in question. For this reason elements such as cobalt, nickel and chromium would be expected in higher quantities in ultrabasic rocks than in acidic rocks, where elements such as barium would be more prevalent. If the origin of a soil can be directly traced to an igneous formation, it is possible to forecast the probable occurrence of its trace elements, but in practice the problem is complicated by weathering and metamorphosis and if, as often the case in north-east Scotland, the surface is derived by glacial drift from sedimentary rocks, the problem becomes individual for each soil considered. These points were illustrated by discussing the range of trace elements found by spectrographic analysis of Scottish soils, in respect of silver, barium, cobalt, chromium, cæsium, copper, gallium, germanium, lanthanum, lithium, manganese, molybdenum, nickel, lead, rubidium, tin, strontium, thorium, titanium, vanadium, yttrium and zirconium.

The occurrence of a given trace element in a soil, however, is not necessarily a guide to its occurrence in plants, and although there exists a general correlation between soil quantities soluble in dilute acetic acid and quantios found in the covering vegetation, trace-element deficiency diseases are sometimes found in plants growing on soils containing abundance. The natural $p \mathrm{H}$ of the soil is an important factor, as evidenced by the lime-induced 'chlorosis' of plants found in parts of England.

In general, trace-element deficiencies of plants and grazing animals can be rectified by incorporating small amounts in fertilizers, as little as $2 \mathrm{lb}$. per acre of a cobalt salt being su ficient to prevent the "sheep pining' of certain pastures in Ross-shire. Among plant diseases in Scotland associated with trace elements were mentioned boron deficiency of turnips and sugar beet in the west and manganese deficiency leading to 'oat sickness' in the north.

(3) Copper, Zinc and Other Trace Elements in Relation to Physiological Function and Enzyms Systems. Dr. H. Mann, in this paper with Prof. D. Keilin, pointed out that, of the numerous trace metals detectable in tissues, definite physiological functions have so far only been assigned to iron, copper and zinc. To these, several distinct purposes can be assigned, of analogous character in all three cases. They either form oxygen carriers or catalyse reactions involving oxidation, reduction, or acid-base equilibrium. In each case the metal has definite physiological properties only when stoichiometrically bound with highly specific protein molecules which, although themselves inactive, determine the pro- 
perties of the metallo-protein compounds and can be limiting factors in their formation. It is the specific protein which determines whether the trace element is to function as carrier of molecular oxygen in the circulating fluid or as catalyst promoting intracellular oxidation in the tissues, or perform any other function.

In dealing with iron, Dr. Mann discussed the rare iron-protein hemerythrin, the commoner ironporphyrin-protein oxygen-carrier $h$ emoglobins and myoglobins, the green $\mathrm{h}$ emoglobin chlorocruorin of certain molluscs, and the oxidizing catalysts cytochrome, peroxidase and catalase. Among the copperprotein compounds are the blue oxygen-carrier hæmocyanins of some arthropods and molluses, the oxidizing catalysts such as the phenolic oxidases which account for the rapid darkening of fruits and vegetables on bruising, and of insect cuticle after emergence from the pupe. The function of the hæmncuprein of red blood cells is not yet known, although copper is recognized as essential for hæmoglobin formation. In the case of zinc, only one enzyme is yet recognized, the carbonic anhydrase of blood corpuscles, gastric mucosa, pancreas and other tissues. Its function is to catalyse the reversible dissociation of carbonic acid into carbon dioxide and water, and so facilitate the removal of oxidation products and the maintenance of acid-base equilibrium in the body. The fact, however, that the distribution of zine is not strictly coincident with that of carbonic anhydrase suggests other zincprotein compounds with other functions.

Of special interest is the enormously high activity of the trace metals in the form of their specific protein compounds. The enzymes are active when present as parts per thousand million, a level at which neither the metal itself nor the protein itself can be detected by any known chemical means.

(4) Enzootic Ataxia or 'Swayback' of Lambs in England in Relation to Copper F'eeding of Ewes During Pregnancy. This contribution took the form of a cinematographic film illustrating the Derbyshire investigations of a group of workers under the general co-ordination of Prof. T. Dalling, recently translated from the chair of animal pathology at Cambridge to the directorship of the Veterinary Laboratory of the Ministry of Agriculture at Weybridge, into a disease of lambs termed 'swayback' in Britain and 'enzootic ataxia' in Australasia and other parts of the world. The disease can be controlled by supplying copperized salt during pregnancy to outwardly healthy ewes, the lambs of which otherwise develop the disease during fotal growth and suffer high mortality incidence in the first week of life. Although the precise role of copper is not yet clear, the quantities of that element in the blood of affected lambs and their mothers is below that of unaffected controls. Unlike certain Australasian pastures, however, affected Derbyshire pastures cannot be incriminated as grossly deficient in copper.

The film illustrated the characteristic spastic paralysis of limbs with resultant inco-ordination dur.ng life, and the pathological lesions found at post-mortem. The latter comprised symmetrical demyelination of the cerebrum and secondary degeneration of the motor tracts of the cord.

(5) Cobalt and Other Trace Elements in Relation to Disease in Australasia. This paper, read by Dr. H. Chick on behalf of Sir Charles Martin, who had personal experience of animal diseases in Australia during his sojourn there about a decade agn. placed in historical perspective the classical researches carried out over the last fifteen years in that continent into diseases of cattle and sheep caused by deficiency of cobalt, of copper, or of both combined.

Along the coast of South and West Australia, areas occur in patches long known by farmers to be unsuitable for rearing ruminants, although they enjoy a rainfall of 20-40 in. and produce abundant herbage throughout the growing period. Animals could be fattened on them but not reared, since if confined to them for more than a few months cattle and sheep began to weaken, without characteristic lesions to suggest a cause, finally dying of starvation in the midst of apparent plenty. In South Australia the soil of these unsound areas consists of unconsolidated wind-blown sand and shells; in West Australia of loamy granitic gravel about five miles from the coast at an altitude of $500 \mathrm{ft}$. In the latter area the disease was termed 'enzootic marasmus' by Filmer, who found that, like the 'bush sickness' of New Zealand formerly attributed by Aston to iron deficiency, it can be prevented and cured by mineral licks containing the iron ore limonite. Very poor response, how. ever, was given by therapeutic treatment with pharmaceutical iron salts, and in following up this observation Filmer subjected the limonite to chemical fractionation. Extracts freed from iron but containing zinc, nickel and cobalt were as active as the original material and trials of these elements separately led to the discovery that enzootic marasmus is a cobalt-deficiency disease preventahle by administration of so little as $0.1 \mathrm{mgm}$. daily for sheep and $0.5 \mathrm{mgm}$. for cattle.

Parallel researches by Marston and others in West Australia were complicated by differences in symp. tomatology. In addition to the progressive weakness of enzootic marasmus, ataxia proceeding to complete inco-ordination of limb movements was ohserved, particularly in lambs and young sheep, and shown by Bull to be associated with demyelination of spinal tracts. After much exhaustive testing of possible causes, from poisonous plants to gross mineral imbalance, a trace element factor was suspected and Jansen's salt mixture, containing zinc, nickel, cobalt, manganese, aluminium, boron, arsenic, molybdenum and copper, along with the usual major elements, was tried. This gave excellent results, and by a process of elimination it was finally ascertained that the required combination was copper and cobalt. Unless both were included the experimental controls succumbed within a year.

Further investigation showed the occurrence of copper deficiencies alone, notably the enzootic ataxia of lambs in West Australia, while the bush-sickness of New Zealand was then found to be due to deficiency of cobalt and not iron. Arising from the Australasian investigations, similar diseases were then identified in many other parts of the world, including the long known 'renguerra' of Peru and the 'swayback' in restricted areas of England.

(6) Sheep 'Pining' in Britain. Mr. W. Lyle Stewart, veterinary investigational officer at Newcastle, dealt mainly with the occurrence of 'pine' in Northumber. land, a wasting disease of sheep associated with anæmia. This is treated as the result of interaction between malnutrition and helminth infestation. Neither factor alone is su ficient to account for death. In fairly large-scale experiments a small ration of mineralized cake containing a variety of trace elements, including copper and cobalt, reduced incidence of the disease, and periodic dosing with anthelmintics achieved the same effect, but much 
the best results were obtained by combining both treatments. In another series of experiments equally good results were obtained by combining fortnightly dosing with mixed trace elements in solution and monthly dosing with phenothiazine as anthelmintic. Live-weight gains of lambs over a short experimental period were $27 \mathrm{lb}$. for the controls, $3 \mathrm{I} \mathrm{lb}$. for trace element dosing, $36 \mathrm{lb}$. for anthelmintic treatment, but $41 \mathrm{lb}$. for the combined treatments.

(7) Fluorine in Human Nutrition. Biochemical aspects were dealt with by Dr. M. M. Murray, a clinical account of fluorine distribution was provided by Dr. D. C. Wilson, and radiological investigations were reported upon by Mr. F. H. Kemp.

Dr. Murray dealt briefly with sources of fluorine in drinking water, the main cause of chronic endemic fluorosis manifested most clearly as 'mottling' of teeth; and with compounds such as fluorspar and cryolite causing industrial fluorosis characterized by osteosclerosis. It was pointed out that fluorine occupies a curious position nutritionally in that very small traces appear to be beneficial, whereas larger traces seriously interfere with bone metabolism. More fluorine was found by American workers in sound teeth than in carious teeth, and 'mottled enamel', occurring where fluorine in drinking water reaches about 1 p.p.m. during the period of development of teeth, is more resistant tocaries. Fluorineaffects the bones at all ages; adult workers exposed to industrial risk develop osteosclerosis but not mottled teeth. Little is known about the precise action of fluorine, but the low concentration at which it inhibits osteogenesis suggests a catalytic effect. Traces of fluorine can pass the placental barrier, and disorganization of calcification occurs in the fœtuses of experimental rats on high fluorine intake.

Mr. Kemp showed lantern slides illustrating cases of human skeletal fluorosis, including 'round back' of children and adults in areas of Great Britain in which mottled teeth are prevalent. It was not claimed that high fluorine intake is alone responsible for interference with spinal ossification in children, but merely that high fluorine in drinking water may influence development of such defects.

Dr. Wilson discussed the relationship between fluorosis and nutritional status, stating that although mottling and staining of teeth are proportional to the amount of fluorine in drinking water, the state of nutrition of the individual determines the character of the enamel and regularity of dentition. Nutritional status also influences the skeletal lesions in chronic endemic fluorosis, and dietary surveys in India have shown much more severe lesions in poor villages than in prosperous neighbouring communities. For early treatment of 'round back' associated with dental fluorosis of children in Oxfordshire, good results can be expected by combining school meals with attention to posture in physical training.

(8) Industrial Fluorosis of Animals in England. Under this title Mr. F. Blakemore, veterinary investigational officer at Cambridge, described an outbreak of industrial fluorosis in farm animals extending for about a mile in the direction of the prevailing winds from a high concentration of kilns in a brick-making district of England. Analysis of pasture grass and other plants showed surface contamination with fluorine compounds and this was traced to the flue gases drifting down from the chimneys, and thence to the high fluorine content of the clay used in brickburning. Cattle are most severely affected and typical cases show lameness and enlarged atrophic bones with fluorine content up to 16,000 p.p.m.; mottling of the permanent incisors occurs in most cattle within the affected belt. Urinary fluorine is high even in animals without pronounced clinical symptoms, and its estimation in catheter samples has proved an excellent method of mapping affected farms. On removal of clinically affected animals from the district, urinary elimination of fluorine continues above normal, with rapid clinical improvement. The content of fluorine in surgically removed bone frag. ments fell rapidly over the first three months, but over the following five months showed little change from the residual high level.

A few parallel observations in the Manehester smoke belt showed no evidence of fluorosis at all.

(9) 'Teart' of Somerset : a Molybdenosis of Farm Animals. Mr. W. S. Ferguson, one of the three Jealott's Hill investigators who established the etiology of this disease a few years ago, described the condition as one only affecting ruminants, chiefly dairy cows, and characterized by scouring and pro. gressive cachexia. The dung becomes watery, foul and greenish yellow; hair covering of Red Devon cattle turns dirty yellow, and that of black beasts a rusty colour. Affected areas comprise about 20,000 acres in central Somerset associated with the Lower Lias geological formation, and smaller regions in north Somerset, Gloucester and Warwick. Spectrographic examination of affected pastures reveals abnormally high molybdenum, up to 100 p.p.m. on the dry matter as compared with 5 p.p.m. for healthy pastures, and the degree of 'teartness' is directly related to the water-soluble molybdenum content, which is highest in lush young grass and lowest in old herbage. The analytical conclusions were supported by reproducing the disease experimentally, by dosing with calculated amounts of sodium molybdate and by top-dressing sound pasture to raise the molybdenum content to that of affected pastures.

In searching for an antidote, it was found that oral ingestion of $2 \mathrm{gm}$. copper sulphate per cow per day prevents scouring and permits grazing of teart pastures throughout the season. Explanation of the mode of operation of the copper, and of the limitation of the molybdenum effects to ruminants, awaits further investigation.

(10) Absorption and Excretion of Trace Elements. Miss E. M. Widdowson, reading a joint paper with Dr. R. A. McCance, pointed out that there are no special characteristics in regard to absorption and elimination of trace elements except in so far as these can be deduced from their known chemical properties. Both absorption and excretion of silver as a trace element are limited by the insolubility of its chloride; in the case of barium by the insolubility of its sulphate. If divalent and capable of forming insoluble phytates and phosphates, as in the case of zinc and manganese, they tend to behave like the physiologically $a^{\prime}$ )undant calcium. If monovalent and characterized by solubility of their salts, they behave like the alkali metals or the halogens. The soluble milligram or so of lithium in daily human food behaves exactly like the concomitant $5,000 \mathrm{mgm}$. of sodium. Elements which cannot be excreted by the kidney in virtue of attachment to serum proteins will react alike, and zine or manganese will tend to behave in the same way as iron.

The dificulties inherent in determining absorption and excretion of any element while the cycle of ingestion, intestinal absorption and partial return to 
the intestine by bile and digestive juices is in progress were stressed, and further parallels drawn between relatively abundant elements such as calcium and magnesium and trace elements such as strontium, tin, cobalt and nickel.

In his final summary of the day's discussion, Prof. C. Harington reviewed a number of the salient features in the light of his own experience of the history of development of the physiology of iodine, stressing the point that although much information on the importance of various trace elements may accumulate, final conviction concerning the significance of any particular one does not really penetrate the scientific consciousness of the community until precise physiological function becomes clear and the actual operative mechanism is biochemically demonstrated.

T. DALLING.

H. H. Green.

\section{STAR MAGNITUDES AND IMAGE DIAMETERS IN PHOTOGRAPHIC PHOTOMETRY}

$\mathrm{F}_{\mathrm{s}}$ ORMULA hitherto employed to determine the relationship between star magnitudes and image diameters on photographic plates have been empirical, and fail in certain circumstances. It is impossible to apply them in the case of bright stars which give diameters larger than a certain limiting value (and this value varies with different formulæ) and, in addition, the formulæ take no account of the effect of star colours. D. L. Edwards has described a new method of investigation which gives very satisfactory results (Mon. Not. Roy. Astro. Soc., 102, 5). The work was carried out at the Norman Lockyer Observatory, Sidmouth. Three different Zeiss triplet lenses were used : (a) apertyre $14 \mathrm{~cm}$., foeal-length $70 \mathrm{~cm}$., (b) aperture $10.4 \mathrm{~cm}$., focal-length $50 \mathrm{~cm} .,(c)$ similar to (b) but stopped down to $2 \mathrm{~cm}$. aperture. The plates used were the Barnet Super Press (blue sensitive emulsion), and Ilford Hypersensitive Panchromatic, which gives a good scale of photovisual magnitudes without a filter. When the panchromatic plates were considered and measured diameters were plotted against H.D. visual magnitudes (only stars of type $A 0$ being used to determine the form of the relation for one colour only) the empirical formula $m=a-b\left(D-k D^{2}\right)$ gave the best fit. In this formula $m$.is the magnitude, $D$ the diameter, and $a, b, k$ are constants.

Measures made on Barnet Super Press plates were treated in the same way, except that photographic instead of photovisual magnitudes were used, and it was found that the above relation held as for the photovisual plates. In addition, the same values of $k$ were also applicable, in spite of the different magnitude scales and of the different types of emulsion used. Good values of $k$ were given by $k=10^{-5}(140-13 C)$, where $C$ is the colour index.

The advantage of the first formula given above is that it has a greater range of application to bright stars than earlier formulæ, and it also allows for colour effect.

Edwards has applied this formula to $\gamma$ Cassiopeiæ. The series of photographs extended over the period June 1, 1940, until March 24, 1942. During 1940 the magnitude variations were more pronounced, but by the end of the year and also throughout 1941 they tended to become steadier. Considerable changes in the spectrum accompanied the more pronounced fluctuations. At, and just preceding, the minima of June 29, 1940, photovisual magnitude $2 \cdot 76$ and photographic magnitude $2 \cdot 64$, and also of September 21, photovisual and photographic magnitude each $2 \cdot 53$, the $H$ lines showed well-separated double emission components with strong central absorption and rather faint 'dish-shaped' absorption fringes. The $\mathrm{He} I$ absorption lines at $4471,4026,3964$ were strong and sharp, and O II absorption rather faint. During the rise to maxima at August 24 and October 7, the magnitudes on these dates being $m_{p v}=2 \cdot 20$, $m_{p}=2 \cdot 06, m_{p v}=2 \cdot 05, m_{p}=2 \cdot 06$ respectively, the $H$ central absorption became fainter and the "dishshaped' absorption stronger. The He I lines became fainter and more diffuse, OII became a little stronger, and $\lambda 3888(\mathrm{He} \mathrm{I})$ very strong.

It was found that the colour index changes were subject to considerable uncertainty and did not show such pronounced correlation with spectrum changes as the magnitude variations. The mean colour index over the whole period was -0.12 , and corresponds to the average colour index of $B 6$ stars. As $\gamma$ Cassio. peiæ is a $B 2$ star, the average colour index of which is $-0 \cdot 30$, its average colour index suggests considerable reddening.

\section{ULTRA-SHORT RADIO WAVE PROPAGATION}

A $T$ a meeting of the Wireless Section of the A Institution of Electrical Engineers on November 4, Dr. R. L. Smith-Rose and Miss A. C. Stickland read a paper describing the results of an analysis of field intensity measurements obtained during the years 1937-39, over the Post Office radio-telephone link between Guernsey and Chaldon, England, on wave-lengths of 5 and $8 \mathrm{~m}$. (frequencies 60 and 37.5 mc. $/ \mathrm{s}$.). The path between the radio stations was almost entirely over sea and about 85 miles in length, of which some 36 miles were outside the optical range. The material analysed was in the form of continuous, twenty-four hours a day, records of the field intensity received at Chaldon from the transmitters at Guernsey.

A quantitative study of the records confirmed the similarity of the type of signal fading on the two wave-lengths, and the lack of both diurnal and true annual variation; on the other hand, the results suggested a long-term secular variation in which the amount of fading on $5 \mathrm{~m}$. tended to increase to a maximum over the period of observations while that on $8 \mathrm{~m}$. decreased. The period of two years over which the observations were taken was not suificient, however, to allow of any conclusions being formed as to an explanation of this trend.

Comparison with meteorological data showed a marked correlation between periods of very little fading and the presence of low-pressure systems, while periods of slow fading recurred at times of anticyclonic conditions. This, together with the fact that fading, while always less in winter than in summer, showed no regular seasonal variation, led to the conclusion that the winter decrease was due to the greater prevalence of low-pressure systems during this season. 